Article

\title{
Carotenoids Overproduction in Dunaliella Sp.: Transcriptional Changes and New Insights through Lycopene $\beta$ Cyclase Regulation
}

\author{
Fatma Elleuch $^{1,2}$, Hajer Ben Hlima ${ }^{3}$, Mohamed Barkallah ${ }^{3}$, Patrick Baril ${ }^{2}$, Slim Abdelkafi ${ }^{3}$, \\ Chantal Pichon ${ }^{2}$ and Imen Fendri ${ }^{1, *(D)}$ \\ 1 Laboratoire de Biotechnologie Végétale Appliquée à l'Amélioration des Cultures, Faculty of Sciences of Sfax, \\ University of Sfax, Sfax 3000, Tunisia; fatma.elleuch@cnrs-orleans.fr \\ 2 Centre de Biophysique Moléculaire (CBM), CNRS UPR 4301, 45071 Orleans, France; \\ patrick.baril@cnrs.fr (P.B.); Chantal.PICHON@cnrs.fr (C.P.) \\ 3 Unité de Biotechnologie des Algues, Biological Engineering Department, \\ National School of Engineers of Sfax, University of Sfax, Sfax 3038, Tunisia; \\ hajer_benhlima@yahoo.fr (H.B.H.); mohamedbarkallah@gmail.com (M.B.); slim.abdelkafi@enis.tn (S.A.) \\ * Correspondence: imen.fendri@fss.usf.tn
}

Received: 16 October 2019; Accepted: 22 November 2019; Published: 10 December 2019

\begin{abstract}
Dunaliella is a green microalga known for its ability to produce high levels of carotenoids under well-defined growing conditions. Molecular responses to the simultaneous effect of increasing salinity, light intensity and decrease of nitrogen availability were investigated in terms of their effect on different metabolic pathways (isoprenoids synthesis, glycolysis, carbohydrate use, etc.) by following the transcriptional regulation of enolase (ENO), 1-deoxy-D-xylulose 5-phosphate synthase (DXS), lycopene $\beta$-cyclase (LCYB), carotene globule protein (CGP), chloroplast-localized heat shock protein (HSP70), and chloroplast ribulose phosphate-3-epimerase (RPE) genes. The intracellular production of carotenoid was increased five times in stressed Dunaliella cells compared to those grown in an unstressed condition. At transcriptional levels, ENO implicated in glycolysis, and revealing about polysaccharides degradation, showed a two-stage response during the first $72 \mathrm{~h}$. Genes directly involved in $\beta$-carotene accumulation, namely, $C G P$ and $L C Y B$, revealed the most important increase by about 54 and 10 folds, respectively. In silico sequence analysis, along with 3D modeling studies, were performed to identify possible posttranslational modifications of CGP and LCYB proteins. Our results described, for the first time, their probable regulation by sumoylation covalent attachment as well as the presence of expressed SUMO (small ubiquitin-related modifier) protein in Dunaliella sp.
\end{abstract}

Keywords: CGP; LCYB; microalgae; modeling; reference gene; transcriptional analysis

\section{Introduction}

The genus Dunaliella is composed of 24 unicellular species, uninucleate [1], enclosed by a glycocalyx [2] and without a rigid polysaccharide wall, allowing a rapid response to hypo or hyperosmotic conditions [3]. The halotolerant Dunaliella salina, the holotype of this genus, is characterized by an exceptional capacity to survive under some environmental stress by producing added value compounds as glycerol, polyunsaturated fatty acids, and a high percentage of $\beta$-carotene reaching $10 \%$ to $14 \%$ of dry weight [2].

The majority of carotenoids are $\mathrm{C}_{40}$ isoprenoids with color ranging from yellow to red and are divided into carotenes and xanthophylls [4]. The $\beta$-carotene molecule is an orange compound, comprising a long conjugated chain of eight isoprene units with a center of symmetry and a $\beta$-cyclohexene ring at each end [5]. It can be found in four possible stereoisomers: 9-cis $\beta$-carotene, 
all-trans $\beta$-carotene, 13-cis $\beta$-carotene, and 15-cis $\beta$-carotene. The amount of 9-cis isoform could reach $60 \%$ of the total carotenes in Dunaliella cells [6].

Carotenoids are extremely beneficial for plants and human health. In photosynthetic organisms, this polyene compound is part of the light-harvesting antenna structure, Photosystem I (PS I) and Photosystem II (PS II), and cytochrome $b_{6} / f$ complex and maintains the integrity of cell architecture [7]. It also protects the photosynthetic apparatus from an injury occurring during photo-inhibition, photo-oxidation [1,8], and high temperature by thermal dissipation [7]. They have a wide range of applications, mainly thanks to their antioxidative properties. In the medical field, they are claimed to prevent or cure many pathologies [1,9] as cataract, cardiovascular diseases, and some cancers [10-13]. In addition, their impressive color allows their exploitation in many food and cosmetic industrial applications as dietary supplements or colorants [14]. D. salina produces primarily the $\beta$-carotene that is the precursor of vitamin A and other carotenoids like zeaxanthin, cryptoxanthin, neoxanthin, [15], phytoene, phytofluene, and lutein.

The carotenogenesis pathway in Dunaliella could be divided into three steps [1], which are the geranylgeranyl pyrophosphate (GGPP) biosynthesis, lycopene biosynthesis, and the generation of different carotenoids with cyclohexane rings. Lycopene $\beta$-cyclase introduces two $\beta$-cyclohexane rings in each extremity of lycopene to generate $\beta$-carotene [16].

This key enzyme, responsible for the biosynthesis of $\beta$-carotene, seems to have the same common ancestor in plants, algae, and cyanobacteria. It exists under two types, epsilon and beta, resulting from an ancient gene duplication event or gene transfer proceeded by endosymbiosis [17]. D. salina possesses one copy of the $L C Y B$ gene in the beta form with 11 exons and 10 introns [18], while epsilon form is supposed to be lost in evolution [17]. The functioning of this enzyme can be inhibited by many factors, such as nicotine [19].

D. salina LCYB (lycopene $\beta$-cyclase) was identified by Ramos et al. [18] and Zhu et al. [20]. LCYB isolated by Ramos et al. is a 584 amino acid protein of $64.5 \mathrm{kDa}$ (ACA34344.1). The findings of Zhu et al. [20] suggested that LCYB might be found as a multi-enzyme complex with another lycopene desaturase.

This biogenesis pathway of $\beta$-carotene is supposed to be regulated both at transcriptional and posttranscriptional levels [21] as it is influenced by many conditions. Many researchers reviewed and tried to pose the possible mechanism involved in its accumulation. In fact, carotenoid accumulation depends on the level and quality of light [8], temperature [22], nutrient availability as nitrogen [23,24], sulfur, iron, and manganese [25], phosphorus [26], salinity [27-29], etc. Stress conditions stimulate the production of reactive oxygen species (ROS), which could play the role of the second messenger for the expression of certain transcription factors, resulting in the accumulation of antioxidant molecules by cells [30]. These authors have suggested that the lipids of the chloroplast membrane are the major receptors of these stimulators. However, until now, this mechanism is still not well explained.

Dunaliella accumulates carotenoids in plastoglobules in the interthylakoid space of the chloroplasts [15]. It was assumed that plastoglobules are derived from the disintegration of the eyespot [31]. These lipid globules contain mainly CGP (carotene globule protein), which is a lipid-associated protein of $38 \mathrm{KDa}$ containing 37 proline residues [32]. This protein was demonstrated to be essential for maintaining the stability of plastoglobules [33].

In this work, we investigated how simultaneous variations of salinity $(\mathrm{NaCl})$, nitrogen concentration, and light intensity affect carotenoids accumulation in Dunaliella sp. and the effect of these conditions on the transcriptional response of genes involved in their production. We also attempted to understand how this stress could affect LCYB molecule by generating its 3D structure. 


\section{Materials and Methods}

\subsection{Microalga and Growth Conditions}

Dunaliella sp. was isolated from the Sebkha of Sidi El Hani (Sousse, Tunisia), having $97 \%$ of similarity with $D$. salina, D. quartolecta, and D. polymorpha [34]. It was cultivated in the F/2 medium [35] based on artificial seawater (ASW). Cells were grown either under unstressed condition (DSC) with a salinity ( $\mathrm{NaCl}$ concentration) equal to $0.46 \mathrm{M}\left(27 \mathrm{~g} \cdot \mathrm{L}^{-1}\right)$, a light intensity of $80 \mu \mathrm{mol}$ photons $\mathrm{m}^{-2}$ $\mathrm{s}^{-1}$, and a Nitrogen source $\left(0.88 \mathrm{mM} \mathrm{NaNO}_{3}, 9.89 \mathrm{mM} \mathrm{KNO}_{3}\right)$ or stressed condition (DSS) with a salinity equal to $2 \mathrm{M}\left(116.88 \mathrm{~g} \cdot \mathrm{L}^{-1}\right)$, a light intensity of $540 \mu \mathrm{mol}$ photons $\mathrm{m}^{-2} \mathrm{~s}^{-1}$, and a Nitrogen source $\left(1 \mathrm{mM} \mathrm{NaNO}_{3}, 0 \mathrm{mM} \mathrm{KNO}_{3}\right)$. For this purpose, an exponential growing starting culture was used to inoculate both control and stressed culture at day 0 . Cultures were maintained at $25^{\circ} \mathrm{C}$ under continuous illumination by a fluorescent lamp.

\subsection{Pigments Extraction}

Pigments were extracted from $2 \mathrm{~mL}$ of cell cultures. To this pellet, $2 \mathrm{~mL}$ of $96 \%$ ethanol was added, and the mixture was sonicated at $40 \mathrm{kHz}$ over $20 \mathrm{~min}$ and then incubated overnight at $4{ }^{\circ} \mathrm{C}$ in the dark. Cells debris was removed by centrifugation $(10,000 \times g, 10 \mathrm{~min})$ to recover pigments in the supernatant. Total chlorophyll and carotenoid amounts were measured by spectrophotometry using equations given by Wellburn and Lichtenhaler [36]. As stated in a previous study, we assumed that the total carotenoid content could be a good indicator of the $\beta$-carotene content as it is the main carotenoid in the pigment composition of D. salina [37].

\subsection{Flow Cytometry Analysis}

To study the intrinsic and extrinsic characteristics of the microalgae cell, flow cytometry analysis was used, as described by Dammak et al. [38]. All cytometric measurements were done using a BD LSR (Becton Dickinson, Franklin Lakes, NJ, USA) equipped with two lasers: argon ( $\lambda$ ex488 nm) and helium-neon $(\lambda e x 633 \mathrm{~nm}$ ). Data were processed with CellQuest Pro software. The diagrams presented in this document were processed online (www.cytobank.org). Argon probe was used as it is associated with the emission channels FL1 (FITC), FL2 (PE), and FL3 (PerCP), which emit at the wavelengths $530 / 30,575 / 26$, and $682 / 13 \mathrm{~nm}$, respectively. The signal intensities of fluorescence were calculated from the mean fluorescence intensity of 10,000 events.

\subsection{RNA Extraction}

Stressed and non-stressed cells at different stages of incubation $(0,4,24,48$, and $72 \mathrm{~h})$ were harvested by centrifugation at $1800 \times g$ for $10 \mathrm{~min}$. RNA was extracted using TRIzol ${ }^{\circledR}$ reagent (Invitrogen, Carlsbad, CA, USA) and further purified using column and wash buffer of the RNeasy Mini Kit (Qiagen, Hilden, Germany). RNA concentrations and quality were determined by the measurement of absorbance $(260 \mathrm{~nm} / 280 \mathrm{~nm})$ using a NanoDrop 2000 Spectrophotometer (Thermo Scientific, Waltham, MA, USA) and agarose gel electrophoresis. Approximately $1 \mu \mathrm{g}$ of the resulting total RNA was used for the synthesis of cDNA using the PrimeScript ${ }^{\mathrm{TM}}$ RT reagent Kit with gDNA Eraser (TaKaRa, Shiga, Japan) according to the manufacturer's protocol.

\section{5. $q R T-P C R$}

\subsubsection{Primers Design and Validation, Reference Gene Selection}

Specific primer pairs for alpha-tubulin ( $\alpha$-TUB), beta-tubulin ( $\beta$-TUB), Enolase (ENO), 1-deoxy-D-xylulose 5-phosphate synthase (DXS), lycopene $\beta$-cyclase (LCYB), chloroplast-localized heat shock protein (HSP70), and chloroplast ribulose phosphate-3-epimerase (RPE) were designed based on the sequences of the corresponding genes in the D. salina genome deposited in GenBank. Whereas, primer pairs for carotene globule protein (CGP) amplification were designed based on the sequence of the corresponding 
gene in Dunaliella bardawil genome, as the sequence among Dunaliella salina is not available. All primer sequences were designed using Primer-BLAST from NCBI and Primer 3 Input 4.0. Primer pairs used for Actin (Act) and $18 S$ rRNA are those cited by [39,40], respectively. Primer set and amplicon characteristics are represented in Table 1. The designed primers obeyed to the following criteria: a length between 18-24 nucleotides, an amplicon length from 100 to $200 \mathrm{bp}$, chosen temperature (Tm) around $60^{\circ} \mathrm{C}$, and avoiding secondary structures and self- and cross-annealing. The specificity of the designed primer was verified by the blast search function (http://www.ncbi.nlm.nih.gov). Furthermore, the optimal concentrations were set after testing three different primer concentrations ranging from 100 to $200 \mathrm{nM}$ to avoid non-specific products and/or primer-dimer artifacts.

Gene coding for Act, 18S RNA, $\alpha-T U B$, and $\beta-T U B$ was used for the screening of the most stable gene in all experiment conditions as they are known to be classic plant reference gene candidates [41]. Quantification cycle $(\mathrm{Cq})$ values were imported into the comprehensive web-based tool RefFinder (http://150.216.56.64/referencegene.php?type=reference), which integrates commonly used reference gene evaluation programs together, including geNorm, NormFinder, Bestkeeper, and the comparative delta Ct methods [41,42]. Results elaborated by RefFinder were confirmed by GeNorm, which is available on excel file [43].

\subsection{2. qPCR Conditions}

qPCR was performed using the Step One QuantiFast SYBR Green PCR Kit (Qiagen, Germany) according to the manufacturer's manual using the LightCycler 480 II (Roche, Basel, Switzerland). Cycling parameters were an initial denaturation at $95^{\circ} \mathrm{C}$ for $5 \mathrm{~min}, 40$ cycles at $95^{\circ} \mathrm{C}$ for $10 \mathrm{~s}$, and $60^{\circ} \mathrm{C}$ for $30 \mathrm{~s}$. A step of fusion by heating from $60^{\circ} \mathrm{C}$ to $95^{\circ} \mathrm{C}$ was added to verify the amplification specificity of each primer pair. Data acquisition and analysis were performed by LightCycler ${ }^{\circledR} 480$ Software, Version 1.5 (Roche). Relative gene expression was calculated using reference genes $\alpha$-TUB. The Cq values were corrected with the estimated PCR efficiency, which was evaluated using a four-point standard curve consisting of a 2-fold dilution series. All reactions were performed in triplicate. The relative quantification of the stressed sample at different times versus non-stressed sample at $\mathrm{T} 0$ was calibrated, and the fold changes were then calculated using the following Equation (1) [44]:

$$
\text { Ratio }=\frac{\left(E_{\text {target }}\right)^{\Delta C P_{\text {target }}(\text { control-sample })}}{\left(E_{\text {ref }}\right)^{\Delta C P_{\text {ref }}(\text { control-sample })}}
$$

Calculated fold changes were analyzed statistically using XLSTAT 2017.5.47467 version (Addinsoft). One-way analysis of variance (ANOVA) followed by Tukey (honest significant difference) HSD test and Dunnett test were applied.

\subsection{Retrieval of Protein Sequences and In Silico Analysis}

The amino acid sequences of LCYB and CGP from Dunaliella sp. were retrieved from the protein database of the National Center for Biotechnology Information (NCBI, http://www.ncbi. nlm.nih.gov/protein/) under the accession numbers of ACA34344.1 and AFU62958.1, respectively. The nucleotide sequence of SUMO (small ubiquitin-related modifier) was searched by blast against the Expressed Sequence Tag (EST) database of Dunaliella sp. Then, the open reading frame (ORF) sequences were generated from the corresponding cDNA (GenBank: HO848823.1) using ORFfinder from NCBI, and the obtained proteins were blasted against the non-redundant protein database. The protein sequence corresponding to ORF2 presented $52.87 \%$ and $49.47 \%$ with SUMO protein from two Chlorophyta Ostreococcus tauri and Monoraphidium neglectum, respectively. The motifs search was performed using the motif search tools from KEGG (Kyoto Encyclopedia of Genes and Genomes) (https://www.genome.jp/tools/motif/). 
Table 1. Primers used in this study and their corresponding amplicons size, melting temperature Tm $\left({ }^{\circ} \mathrm{C}\right)$ based on melt curve analysis, amplification efficiency E $(\%)$, and their reference or access number.

\begin{tabular}{|c|c|c|c|c|c|c|c|}
\hline Gene Name & Abbreviation & & Primer Sequence $\left(5^{\prime}->3^{\prime}\right)$ & Amplicon Size (bp) & $\operatorname{Tm}\left({ }^{\circ} \mathrm{C}\right)$ & E (\%) & Reference/Access Number \\
\hline \multirow{2}{*}{ Actin } & \multirow[b]{2}{*}{ Act } & $\mathrm{F}$ & ACCACACCTTCTTCAACGAG & \multirow{2}{*}{150} & \multirow[b]{2}{*}{86.76} & \multirow{2}{*}{111.35} & \multirow{2}{*}{ [39] } \\
\hline & & $\mathrm{R}$ & GGATGGCTACATACATGGCA & & & & \\
\hline \multirow{2}{*}{$18 S$ RNA } & \multirow{2}{*}{$18 S$} & $\mathrm{~F}$ & TTGGGTAGTCGGGCTGGTC & \multirow{2}{*}{-} & \multirow{2}{*}{83.2} & \multirow{2}{*}{92.6} & \multirow{2}{*}[40]{} \\
\hline & & $\mathrm{R}$ & CGCTGCGTTCTTCATCGTT & & & & \\
\hline \multirow{2}{*}{ Alpha tubulin } & \multirow{2}{*}{$\alpha-T U B$} & $\mathrm{~F}$ & GAGATCACCAACGCTGCCTTTGA & \multirow{2}{*}{105} & \multirow{2}{*}{86.03} & \multirow{2}{*}{106.2} & \multirow{2}{*}{ JF346103.1 } \\
\hline & & $\mathrm{R}$ & CACCACATCACCGCGGTACAT & & & & \\
\hline \multirow{2}{*}{ Beta tubulin } & \multirow{2}{*}{$\beta-T U B$} & $\mathrm{~F}$ & AGGAGGGCGAGTTTGAGGGT & \multirow{2}{*}{137} & \multirow{2}{*}{83.12} & \multirow{2}{*}{92.4} & \multirow{2}{*}{ DQ080916.1 } \\
\hline & & $\mathrm{R}$ & AGCGCGGTGGACTTGAACAG & & & & \\
\hline \multirow{2}{*}{ Enolase } & \multirow{2}{*}{ ENO } & $\mathrm{F}$ & TGAAGGGCATGGACCCCAGG & \multirow{2}{*}{123} & \multirow{2}{*}{85.66} & \multirow{2}{*}{97.23} & \multirow{2}{*}{ KM008612.1 } \\
\hline & & $\mathrm{R}$ & TGGCAGTTGCCAGGGAGACA & & & & \\
\hline \multirow{2}{*}{$\begin{array}{l}\text { 1-deoxy-D-xylulose } \\
\text { 5-phosphate synthase }\end{array}$} & \multirow{2}{*}{ DXS } & $\mathrm{F}$ & AGGACTTACGCCTGGCCACAT & \multirow{2}{*}{102} & \multirow{2}{*}{85.67} & \multirow{2}{*}{94.86} & FI469276.1 \\
\hline & & $\mathrm{R}$ & GCAGCAACCAGGCCAGTGTT & & & & $5 J 4092 / 0.1$ \\
\hline & & $\mathrm{F}$ & CCTGCAATCACCACAGGCGG & & & & \\
\hline Lycopene $\beta$-cyclase & $L C Y B$ & $\mathrm{R}$ & GGGGGTTTCTGGCGTCCTCT & 130 & 87.91 & 97.1 & EU32/8/6.1 \\
\hline Carotene globule & & $\mathrm{F}$ & GGCAACCGAGGCAGTGACTACCA & 104 & 8518 & & IX6466771 \\
\hline protein & CGP & $\mathrm{R}$ & GGAACTCCGGTGGACATCTGGTT & 104 & 85.18 & 111 & J人0400//.1 \\
\hline Chloroplast-localized & HSP70 & $\mathrm{F}$ & TGCAGGCTGGTGTGCTGTCT & 124 & 87.88 & 99.03 & AJ271605.2 \\
\hline heat shock protein & HОРТ & $\mathrm{R}$ & AGGGTGGTGTTGCGGGTGAT & 124 & $8 / .88$ & 99.03 & \\
\hline Chloroplast ribulose & $R P E$ & $\mathrm{~F}$ & TGATCAAGGACCTGGGCTGCAA & 120 & 85.96 & 97.33 & |6108.1 \\
\hline phosphate-3-epimerase & RPE & $\mathrm{R}$ & AGCCAGGGTTCACGGACATGA & 120 & 85.96 & 91.33 & JF340108.1 \\
\hline
\end{tabular}


Prediction of posttranslational modifications was performed with SIB (Swiss Institute of Bioinformatics) bioinformatics tools from the ExPASy bioinformatics resource portal (www.expasy. org). Sumoylation was further assessed using SUMOplot (http://www.abgent.com/tool/sumoplot). Multiple sequence alignment of LCYB sequences was performed with Clustalw using default parameters [45] and formatted with Espript 3.0 [46]. TMHMM server (http://www.cbs.dtu.dk/services/ TMHMM) [47] was used to predict transmembrane helices.

\subsection{Three-Dimensional Protein Modeling}

Homology modeling was performed with the SWISS-MODEL server (http://www.expasy.org/ swissmod/). For the LCYB model, the crystal structure of geranylgeranyl reductase (PDB ID 4OPL) was used as a template since no structure of LCYB was found in the database [16]. The modeled structure was further validated by performing the Ramachandran map analysis using the PROCHECK server [48]. However, the generated model was truncated in its $\mathrm{N}$-terminal and C-terminal ends due to the non-total coverage sequence with the template. For SUMO protein, the solution structure of SUMO from Trypanosoma brucei was used as a template (PDB ID 2k8h.1), and the generated model was equally validated.

The models were viewed using The Discovery Studio software [Dassault Systemes BIOVIA, Discovery Studio Modeling Environment, Release 4.5, 2015] and The PyMol Molecular Graphics System v1.2r3 pre (Schrödinger, LLC, New York, NY, USA). Possible active sites of LCYB were determined using the CASTp web server [49].

\subsection{Flavin Adenine Dinucleotide (FAD)-Docking}

The FAD docking was performed using the Galaxy web server, where parameters are set as default. GalaxyDock performs conformational space annealing (CSA) global optimization to find the optimal binding pose of a ligand both in the rigid-receptor mode and the flexible-receptor mode [50].

\section{Results}

\subsection{Characterization of Dunaliella in the Two Cultural Conditions}

\subsubsection{Influence of Stressed Condition on Cell Growth}

Dunaliella sp. was grown in F/2 medium under unstressed (DSC) and stressed (DSS) conditions. In the latter case, a rise in salinity and light intensity was applied against a decrease in nitrogen source. The follow-up of the growth among 29 days showed that DSS maintained the same growth rate as DSC during the first 6 days of culture (Figure 1a). Subsequently, DSC continued to grow during the follow-up while DSS appeared to stop dividing.

\subsubsection{Pigments Accumulation}

The production of pigments by DSC and DSS during one month of culture was followed by biochemical quantification. For DSC, the increase in pigment concentration over the time was due to the increase in cell numbers and not to an intracellular over-accumulation as we noticed that the concentrations presented in $\mu \mathrm{g} / \mathrm{mL}$ increased over time (Figure $1 \mathrm{~b}$ ) whereas those presented in $\mathrm{pg} / \mathrm{cell}$ were almost constant (Figure 1c). Whereas for DSS, the metabolism of cells was totally oriented to carotenoid accumulation. Chlorophyll production measured in the culture $(\mu \mathrm{g} / \mathrm{mL})$ and on the intracellular side ( $\mu \mathrm{g} / \mathrm{cell})$ were maintained at a basal level (Figure 1b,c). Carotenoids production in culture and intracellularly increased simultaneously (Figure 1b,c).

The accumulation of carotenoids by DSS was greater than that in DSC. For example, the number of carotenoids produced was $3.38 \pm 0.33$ and $17.96 \pm 0.67 \mathrm{pg} / \mathrm{cell}$ in DSC and DSS, respectively, on day 17 , which represents a five-fold increase. The ratio of carotenoids/chlorophylls in DSS culture vs. DSC culture was highly increased, reaching 18 times at the end of the exponential phase. 

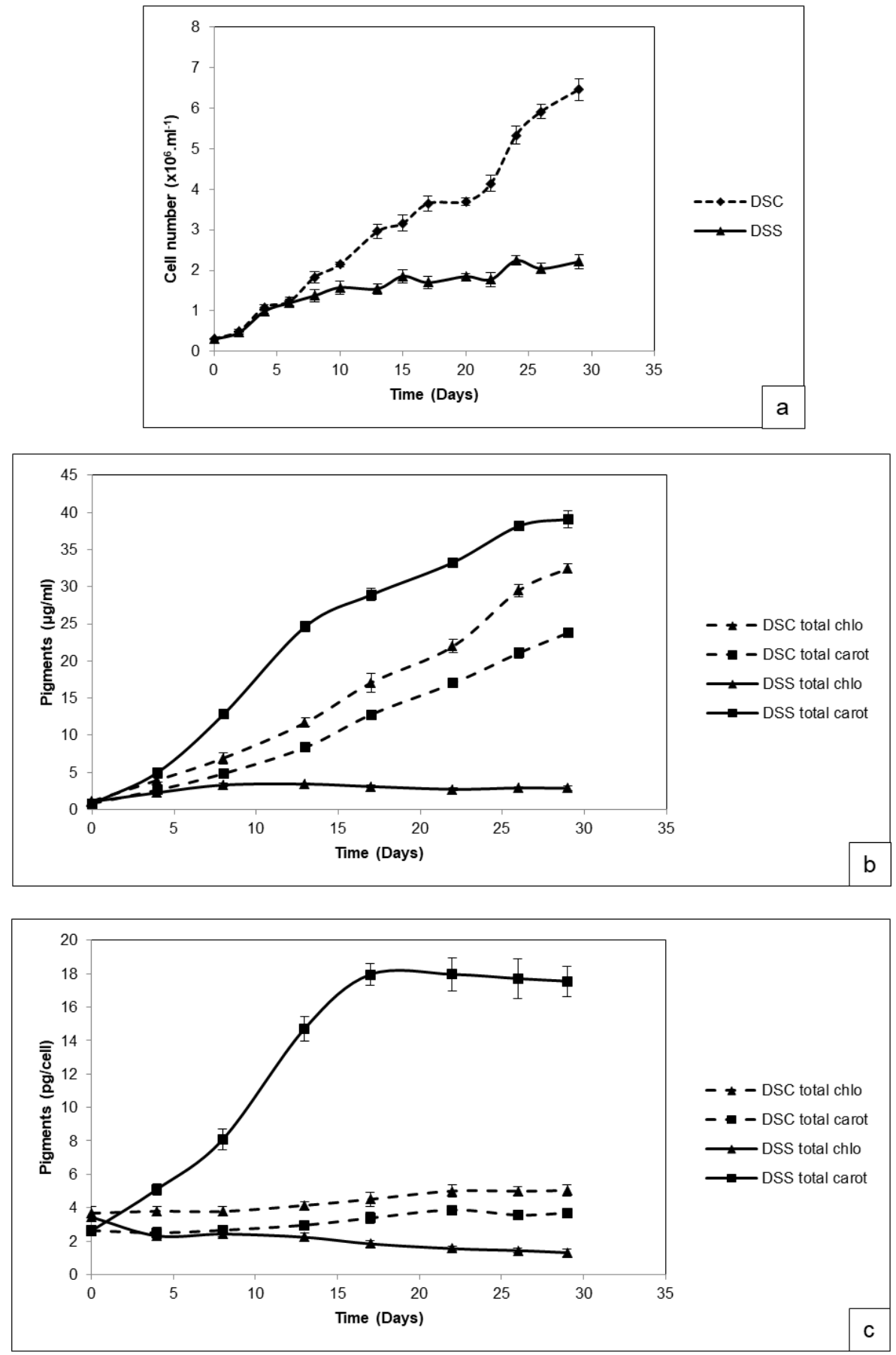

Figure 1. Follow-up of growth kinetic of Dunaliella sp. cultivated under unstressed (DSC) and stressed (DSS) conditions by cell counting through a hemocytometer (a). Pigment quantification among DSC and DSS expressed as $\mu \mathrm{g} / \mathrm{mL}$ (b) and pg/cell (c) for 29 days.

\subsubsection{Flow Cytometry Analysis}

Cell populations were selected based on cell size FSC (Forward Scatter) and granulation SSC (Side Scatter) (Figure 2a). For DSC, there were two subpopulations with different granularity characteristics: a major sub-population (65\%) with high SSC and a sub-population (35\%), which was less grainy. While for DSS, a unique cell population was present resembling the major subpopulation of DSC. 


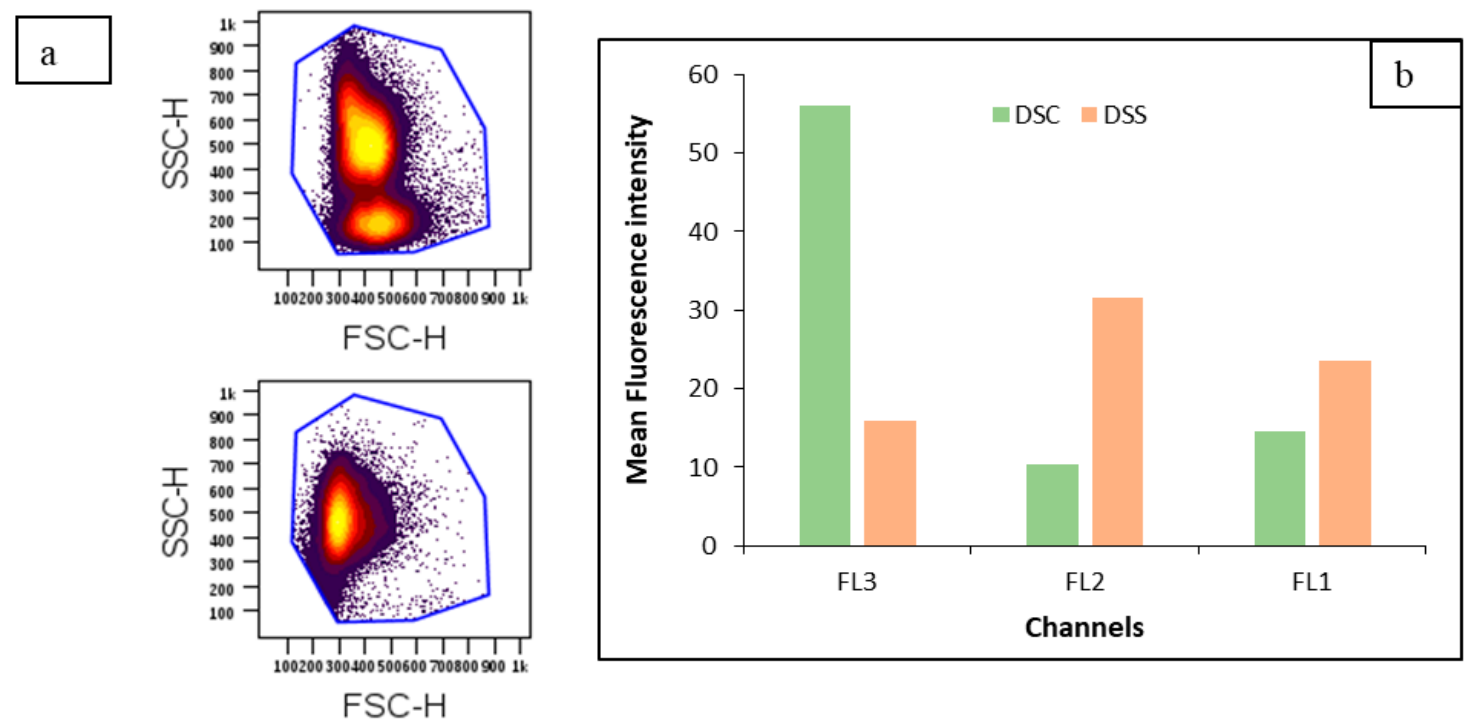

Figure 2. Flow cytometry analysis: counters plots control of population gated under unstressed condition ((a). above) and stressed condition ((a). below). Mean fluorescence intensities of Dunaliella sp. Cells were obtained upon excitation with FL1 (FITC, 530/30 nm), FL2 (PE, 575/26 nm), and FL3 lasers (PerCP, 682/13 nm) (b).

The mean fluorescence intensities of the stressed and unstressed cells were also determined (Figure 2b). Fluorescence was detected on the channel FL1, FL2, and FL3. The red fluorescence emission signal FL3 $(682 / 13 \mathrm{~nm})$ was more adequate to detect the fluorescence of chlorophyll $a$ as its fluorescence emission spectrum is characterized by a major peak at $683 / 20 \mathrm{~nm}$, attributable to the activity of PSII [51]. Stressed cells had a reduced fluorescence emission in FL3 corresponding to a regression of intracellular content of chlorophyll measured by biochemical methods. In contrast, an important increase of fluorescence emission was detected through FL1 and FL2 channels, which was likely due to the overproduction of carotenoids in stressed cells compared to unstressed ones [52,53].

\subsection{Transcriptional Analysis}

\subsubsection{Evaluation of Reference Gene Stability}

The comprehensive ranking generated by RefFinder for the total experimental conditions revealed that alpha-tubulin $(\alpha-T u b)$ was the most stable gene followed by the actin gene (Act), while 18S RNA was the least stable gene (Supplementary Figure S1a). The analysis via GeNorm showed an expression stability value (M) less than 1.5 for all tested genes, which indicated that they were all accepted as reference gene candidates (Supplementary Figure S1b). Nonetheless, GeNorm classified $\alpha$-Tub and Act as the best stable reference genes since they had lower $\mathrm{M}$ values compared to those of $18 \mathrm{~S}$ RNA.

\subsubsection{Gene Expression Profile under Stressed Conditions}

A follow-up of the expression of some genes involved in the carotene accumulation process during the first $72 \mathrm{~h}$ of stress time was processed by quantitative PCR. The first gene followed was ENO involved in the glycolysis cycle and giving an idea about carbon origin (polysaccharide degradation, photosynthesis, etc.) and destiny (isoprenoids synthesis, carbohydrate synthesis, etc.) in the cell. Its transcript level decreased 0.48 times during the first $24 \mathrm{~h}$ of stress. Then, it tended to re-stabilize after $72 \mathrm{~h}$ by having a relative expression level close to 1 (Figure 3a) and without a significant difference in its expression with unstressed cells (Figure 3g). On the other hand, the DXS mRNA level doubled after $24 \mathrm{~h}$ of stress (Figure $3 \mathrm{~b}$ ), while after $72 \mathrm{~h}$, the comparison with unstressed culture showed a significant decrease in its expression level (Figure 3g). 

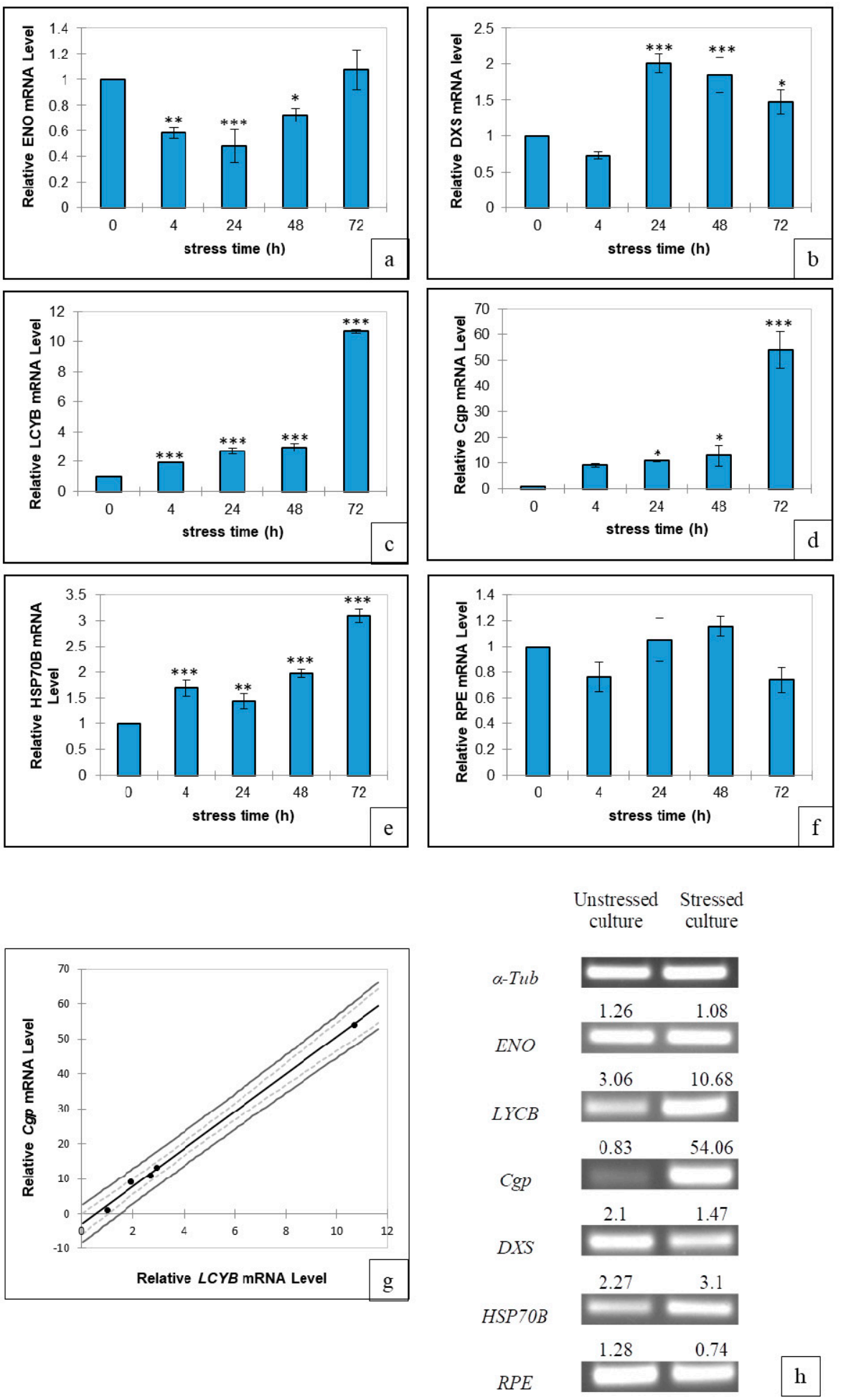

Figure 3. Gene expression levels as a function of stress time. The amounts of ENO (a), DXS (b), $\operatorname{LCYB}(\mathbf{c}), C G P(\mathbf{d}), H S P 70$ (e), and RPE (f) mRNA were normalized against that of the $\alpha$-Tub gene. Agarose gel electrophoresis of the selected gene in Dunaliella sp. under stressed and unstressed conditions upon $72 \mathrm{~h}$ of cell culture $(\mathrm{g})$. Bands intensity correlates with values found by qPCR quantification. Linear regression between the relative expression of $L C Y B$ and CGP, showing a linear relationship between the expressions of these two genes (h). An asterisk indicates a significant difference between gene expressions at different stressed times, according to the one-way ANOVA test followed by Tukey test. * $p<0.05 ;{ }^{* *} p<0.005 ;{ }^{* * *} p<0.001$. Data are expressed as means $\pm \mathrm{SD}(\mathrm{n}=3)$. Model, -...- confidence interval (Mean 95\%), __ confidence interval (obs. 95\%). 
The two genes $L C Y B$ and CGP, which are directly implicated in carotene accumulation, showed the most important rise. Data showed that their expression was increased since $4 \mathrm{~h}$ of stress time (Figure $3 \mathrm{c}, \mathrm{d}$ ) at an exponential pace. For the $L C Y B$ gene, its expression was found to be about 3 -fold higher in stressed culture than the unstressed one during the first $72 \mathrm{~h}$ (Figure 3g). However, for CGP, the expression level in the stressed cell was very high; it was improved by almost 11 -fold at $24 \mathrm{~h}$ (Figure $3 \mathrm{~d}$ ). There was a drastic increase in their expression between $24 \mathrm{~h}$ to $72 \mathrm{~h}$ of stress conditions: up to 10-fold for $L C Y B$ and to 54 -fold for CGP (Figure 3c,d). We noticed also a positive correlation in their mRNA expression $\left(R^{2}=0.997\right)$.

The less important increase was registered in HSP70B mRNA expression level, where the increase reached 3 and 2.27 times at $72 \mathrm{~h}$ in stressed and non-stressed conditions, respectively (Figure 3e,g). Chloroplast ribulose phosphate-3-epimerase (RPE) transcript level showed no significant variation during the first $72 \mathrm{~h}$ of stress (Figure $3 \mathrm{f}, \mathrm{g}$ ).

\subsection{In Silico Analysis}

The following in silico analysis was focused on the two genes showing the most important changes in their transcriptional levels. The motif search results showed that CGP proteins presented a SOUL heme-binding protein motif (PF04832) ranged from residue 283 to residue 350, while LCYB possessed FAD-binding motifs (PF00890), ranging from residue 123 to residue 154.

Prediction of posttranslational modifications (PTMs) for CGP showed four putative protein kinase $\mathrm{C}$ phosphorylation sites distributed in the $\mathrm{N}$ terminal part, two probable $\mathrm{N}$-myristoylation sites, and two sumoylation sites (Table 2). On the other hand, LCYB was found to have eight probable protein kinase $\mathrm{C}$ phosphorylation sites mostly distributed in its $\mathrm{N}$-terminal part, one $\mathrm{N}$-glycosylation site (residue 51), six N-myristoylation sites, and one high probability sumoylation site, as well as two sumoylation interaction motifs (Table 2).

Table 2. Putative SUMO (small ubiquitin-related modifier) interacting motifs in CGP (carotene globule protein) and LCYB (lycopene $\beta$-cyclase), showing scores of predicted sites (bold) and the lysine residue (underlined) implicated in interaction with SUMO.

\begin{tabular}{cccc}
\hline Enzyme & Position & Group & Score \\
\hline \multirow{2}{*}{ CGP } & K308 & WLLGM AKPE DEAKK & 0.79 \\
& K262 & AVSEA FKKEG ETEIS & 0.68 \\
\hline \multirow{2}{*}{ LCYB } & K271 & HARKL VKYYD QEFNP & 0.93 \\
\hline & $124-128$ & QRQPAADLLVVGSGPSGLA & 0.70 \\
& $149-153$ & AGGFSVCVIDLDPYAPMIP & 0.62 \\
\hline
\end{tabular}

\subsubsection{Enzyme Modeling}

An investigation of CGB, LCYB, and SUMO (small ubiquitin-related modifier) protein 3D structures was undertaken to understand or find possible molecular determinants related to their up-regulation. However, only LCYB and SUMO protein were successfully modeled, since no structural PDB files having an acceptable identity with CGP were found in the database. Thus the following part was essentially focused on LCYB molecular study and its probable interaction with SUMO protein in Dunaliella.

\subsubsection{Alignment Analysis}

The amino acid sequence of LCYB from D. salina (accession number: ACA34344.1) was compared with those of known $\beta$-lycopene cyclase homologous proteins (Figure 4). D. salina LCYB showed high similarity with many $\beta$-lycopene cyclases from other microalgae, e.g., $68 \%$ identity with that from Haematococcus lacustris (AAO64977.1), 65\% with that from Chlamydomonas eustigma (GAX83195.1). In contrast, less identity was observed with plant LCYB (50\% with that from Arabidopsis thaliana 
(AAA81880.1)) and very low identity with that from cyanobacteria (33\% with LYBC from Acaryochloris marina (WP_012166204.1). The sequence alignment also revealed that D. salina LCYB exhibited $\mathrm{N}$-terminal and C-terminal insertions when compared to plant and cyanobacteria LCYB in addition to an internal insertion of 15 residues corresponding to the $\alpha 6$ helix in the generated 3D model. Several conserved regions in the protein sequences already identified in other lycopene cyclases from bacteria and plants were also found in D. salina LCYB [18]. Amongst these conserved sequences, PTFLYAM and FLEETSL, highlighted in red in Figure 4, were involved in the formation of $\beta 12$ and $\beta 13$ strands. To further understand the role of these conserved regions in the enzyme activity, we proposed further investigation of the 3D model.

\subsubsection{Overall 3D Model of D. salina LCYB}

Because no structure has been reported in the LCYB family, the crystal structure of geranylgeranyl reductase from a Sulfolobus acidocaldarius strain, which displays a $27 \%$ sequence identity with $D$. salina LCYB, was used as a template, as described previously by [16].

The overall structure of the enzyme could be divided into two distinct domains: a catalytic domain involving a FAD binding site, as well as a substrate-binding site and a transmembrane domain (Figure 5). The catalytic domain belongs to the Rossmann-fold family structure, consisting of a core height-stranded $\beta$-sheet flanked by four $\alpha$-helices. In our case, the catalytic domain also comprised of residues Gly128-Ser129-Gly130-Pro131-Ser132-Gly133, known as a G-x-G-x-x-G motif, for nucleotide-binding [54].

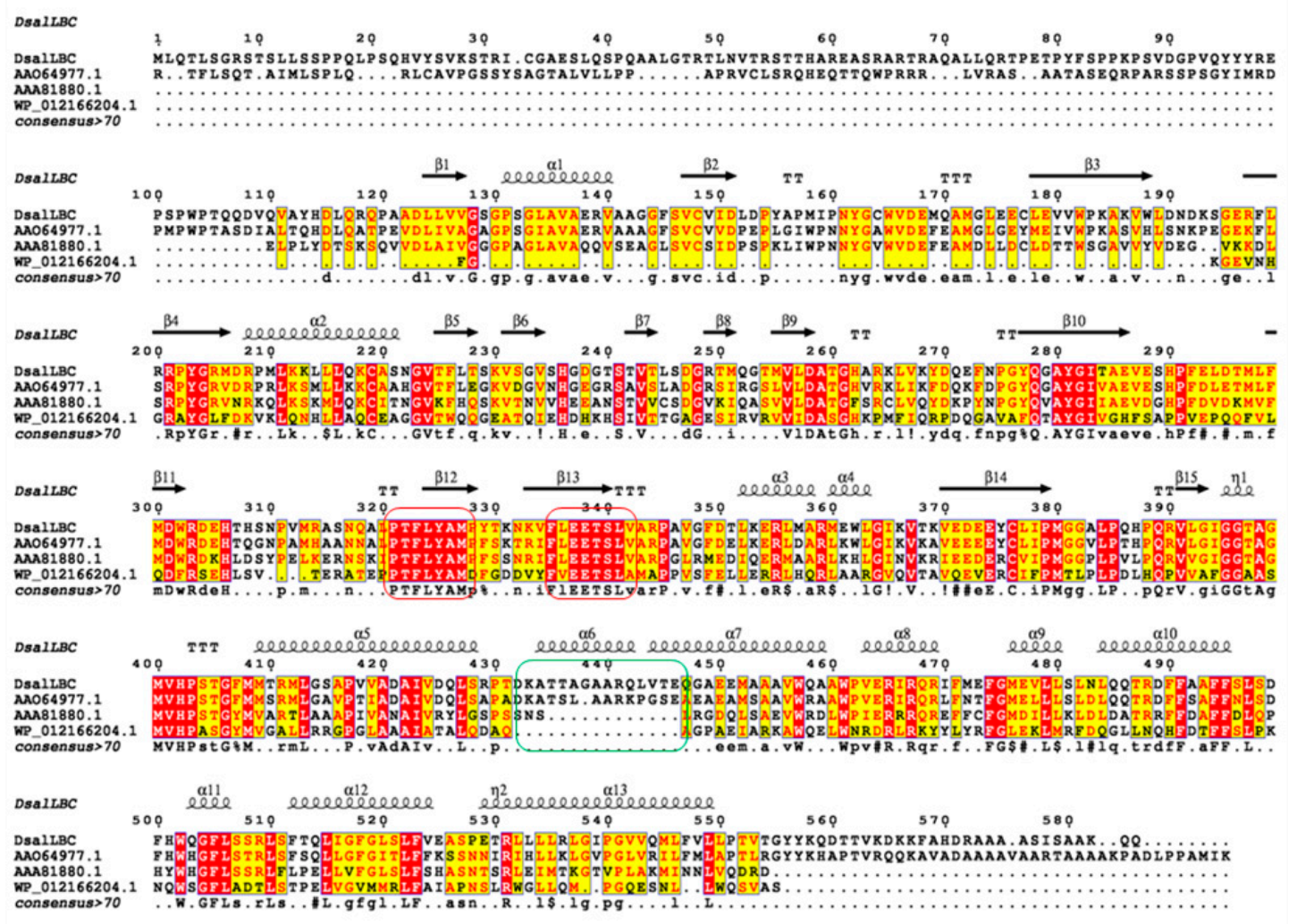

Figure 4. Multiple sequence alignment of LCYB from D. salina in comparison to other LCYB. The secondary structure elements of the generated 3D model indicate DsalLBC: Dunaliella salina LCYB (accession number: ACA34344.1), AAO649777.1: accession number of LCYB from Haematococcuslacustris, AAA81880.1: accession number of LCYB from Arabidopsis thaliana, WP_012166204.1: accession number of LCYB from Acaryochloris marina. Internal insertion corresponding to $\alpha 6$ helix is shown in a green frame, and the conserved sequences, PTFLYAM and FLEETSL, are highlighted in a red frame. Strict $\beta$-turns are presented as TT letters, and strict $\alpha$-turns are shown as TTT. 


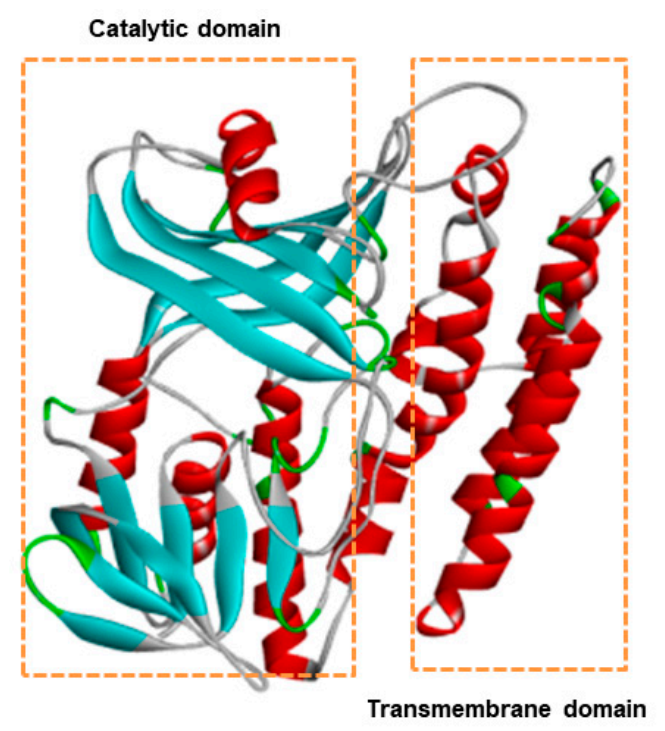

Figure 5. Ribbon representation of the LCYB 3D model, showing the catalytic domain and the transmembrane domain.

The second domain consisted of only three large helices covering the total length of the enzyme, which are suspected to constituting the transmembrane part of the enzyme, as predicted by the TMHMM server.

Calculations of the size and shape of binding sites performed using the CAST program (Figure 6) demonstrated the presence of a small cavity for FAD-binding (radius probe was set to 2), with a total volume of $139.5 \AA^{2}$, and a larger cavity for the substrate binding (radius probe was set to 1.4), with a total volume of $480.14 \AA^{2}$ and an interior length of about $35 \AA$, able to accommodate a large and hydrophobic substrate like lycopene.

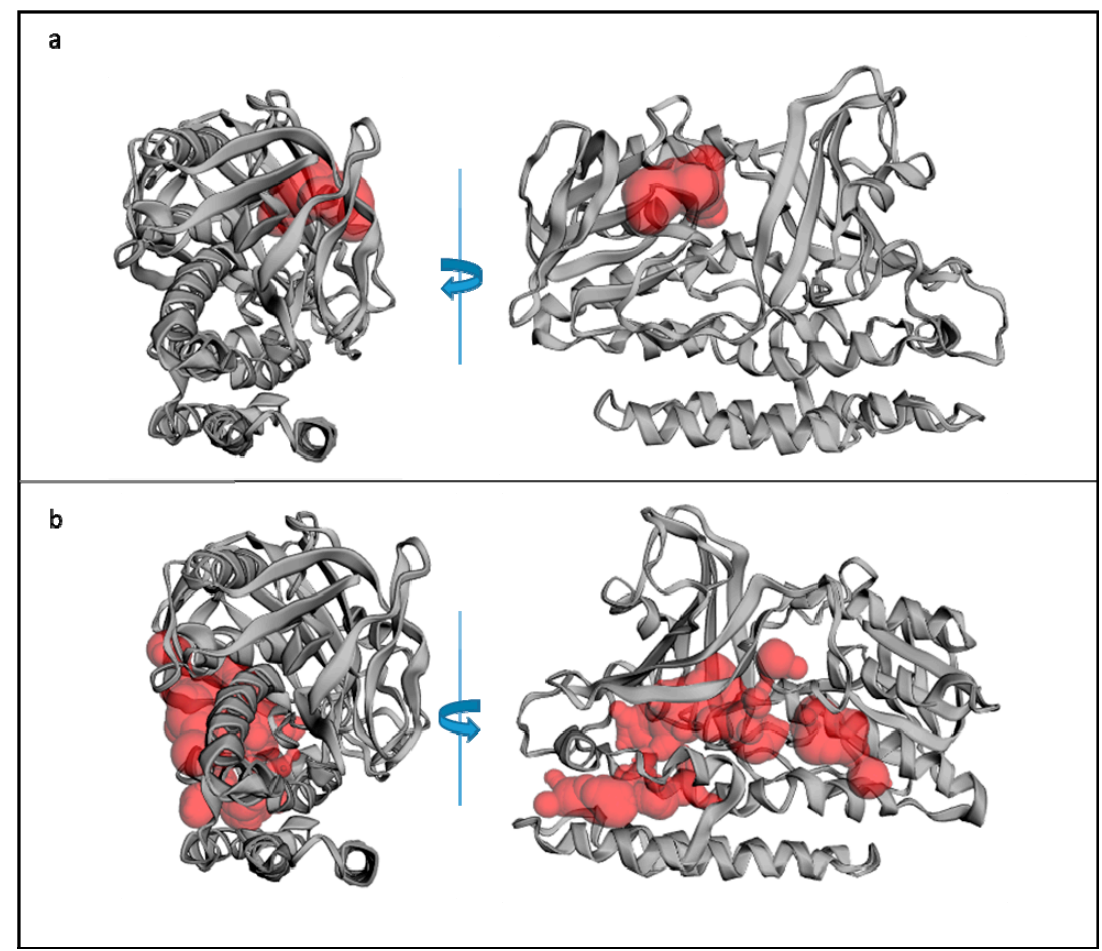

Figure 6. The volume (red) of the probable LCYB Flavin Adenine Dinucleotide (FAD) binding site (a) and substrate binding site (b), calculated using the CAST program. 


\subsubsection{Overall 3D Model of D. salina SUMO Protein}

The predicted structure of SUMO consisted of two $\alpha$-helices $(\alpha 1,41-53 ; \alpha 2,74-79)$ and one twisted $\beta$-sheet $(\beta 1,19-25 ; \beta 2,32-37 ; \beta 3,61-63 ; \beta 4,85-89)$. The $\beta$-sheet consisted of four antiparallel $\beta$-strands (Figure 7a). The structure represented typical ubiquitin-like fold; in fact, the structural comparison showed that the Root Mean Square Deviation (RMSD) value between SUMO from Dunaliella and human SUMO-Smt3 (PDB ID: 1WM3) was 2.1 A. The 3D model of SUMO was equally highly similar to that of Saccharomyces cerevisiae Smt313 (PDB ID: 3UF8) with an RMSD of $2.1 \AA$, reinforcing the hypothesis of the SUMO protein conservation among eukaryotes [55].
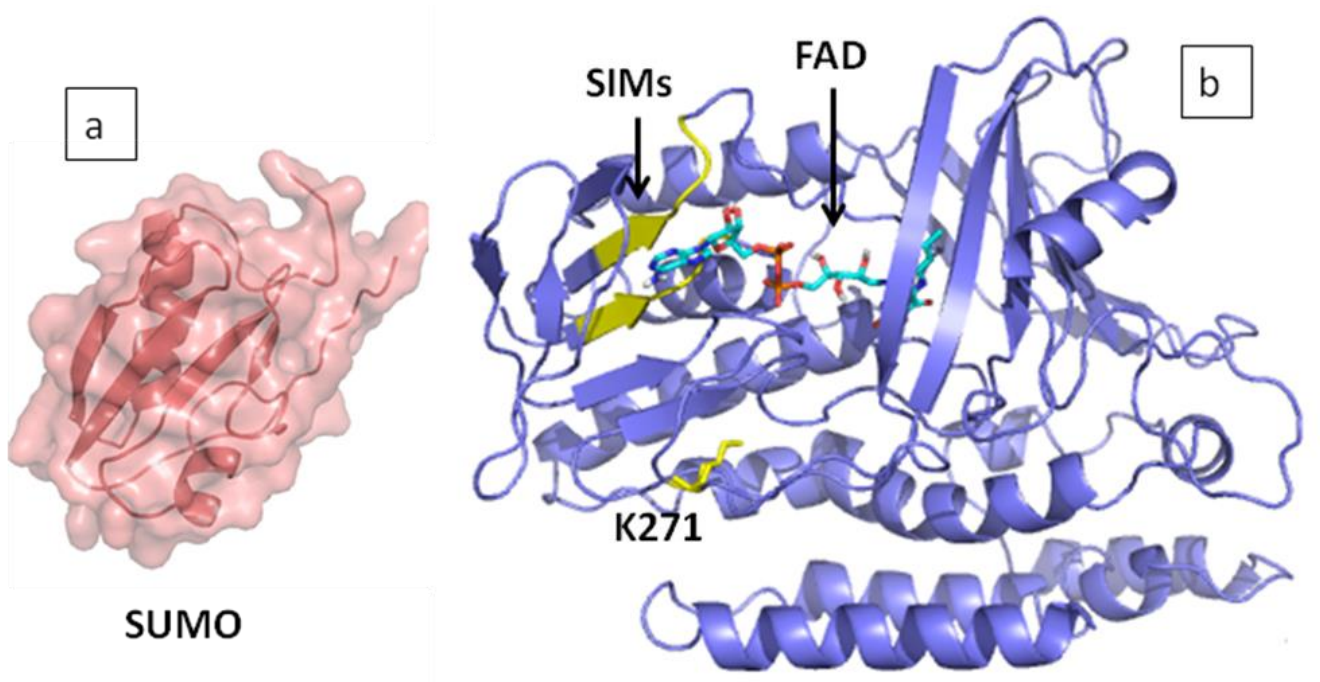

Figure 7. 3D model of SUMO (small ubiquitin-related modifier) protein from Dunaliella sp. (a) 3D model of LCYB, showing docked FAD molecule, SUMO interaction motifs, and SUMO lysine site in yellow color (b).

\section{Discussion}

Dunaliella is a green microalga, well-known by its high production of carotenoids under specific conditions. In this context, we characterized carotenoids production among an isolated strain of Dunaliella sp. cultured under two conditions: unstressed and stressed. The growth rate was influenced by the stress condition, causing a decrease in the DSS growth rate after a week. This was probably due to the depletion of the nitrogen source initially used in the medium. Similar results were also found by Sánchez-Estudillo et al. [56], where D. salina grown under nitrogen limitation maintained the same growth rate as those under nitrogen sufficiency during 8 days and then decreased to the half in about 20 days. The decrease in cell number was accompanied rather with an increase in intracellular carotenoids accumulation and a decrease of chlorophyll amount. Lv et al. in 2016 [21] studied the effect of nutrition depletion on carotenoid production that increased from approximately $2 \mathrm{pg} / \mathrm{cell}$ in complete medium to $9 \mathrm{pg} / \mathrm{cell}$ in nitrogen-depleted medium on day 15 . This observation is in agreement with a previous study showing that the limitation of nitrogen availability accompanied by an increase of salinity and light intensity induced carotenoid accumulation [34]. The increase of salinity engenders also an increase in glycerol and polysaccharide synthesis accompanied by starch degradation [57-59].

For a better characterization of microalgae cells, they were subjected to flow cytometry analysis. Among DSC, we noticed the presence of two populations, which could be due to different evolution cells stage. The analysis of cells at the end of the exponential phase did not permit to display the increase in size and volume of DSS cells versus DSC. Davidi et al. [32] showed that during the first day of environmental stress, cells accumulated lipid globules, causing an increase of cell granularity. After two days, this granularity declined as the stress level would be reduced due to the increase in 
$\beta$-carotene accumulation, and the cell's granularity would become almost like the unstressed one [60]. Based on autofluorescence proprieties of chlorophylls and carotenoids pigment, we confirmed the deviation of Dunaliella metabolism to carotenoids accumulation. In view of this change observed at the phenotypic level, we decided to analyze its response during the first three days of stress, at the transcriptional level of ENO, DXS, LCYB, CGP, HSP70, and RPE genes. For this purpose, the first step was the determination of the best reference gene, which appeared to be the $\alpha$-Tub. Two other studies have also reported the stability of the $\alpha$-Tub gene under severe conditions, one of which was conducted with Dunaliella sp. grown under high light stress [61]. Similarly, a second study realized with Syntrichia caninervis under abiotic stress; the $\alpha$-Tub gene was also found to be stable amongst 15 reference genes, and $18 S$ was the less unstable one [41].

Enolase is a ubiquitous enzyme that catalyzes the penultimate reversible step of glycolysis, which is the unique dehydration of D-2-phosphoglycerate (2-PGA) to phosphoenolpyruvate (PEP) [62]. Its regulation is a key step in the orientation of the organism's metabolism to glycerol or tricarboxylic acid formation [63]. In our study, we found that the transcript level of ENO declined during the first $24 \mathrm{~h}$ of stress, which was in accordance with results founds by Xia et al., reporting a decrease in mRNA expression and ENO activity during $12 \mathrm{~h}$ of hyperosmolarity stress [59]. The expression of ENO tended to increase and restabilize at $72 \mathrm{~h}$ of culture with a relative expression level close to 1 (Figure 3a) and similar to that of DSC (Figure 3h). The same profile was found by Ruan et al., where under hypersaline stress $(3 \mathrm{M})$, the expression level of ENO protein and its activity decreased after $3 \mathrm{~h}$ of stress among D. salina and re-increased at $6 \mathrm{~h}$ [62]. The authors explained that the down-regulation of ENO inhibited the transformation of 2-PGA to pyruvate, which decreased the amount of available carbon for the tricarboxylic acid cycle and the formation of PEP. Dunaliella is indeed capable of surviving under hyperosmotic stress, thanks to the rapid accumulation of osmoprotectants like glycerol. In this condition, starch reserved in the chloroplast will be degraded into glucose to be converted to glycerol [2]. As a result, 2-PGA and then DHAP (dihydroxyacetone phosphate) will be accumulated in the middle of the glycolysis pathway. The DHAP is then transformed via GPDH (glycerol-3-phosphate dehydrogenase) and GPP (glycerol-3-phosphate phosphatase) to glycerol. The restabilization of ENO gene expression after $72 \mathrm{~h}$ allowed a sufficient supply of carbon to PEP synthesis and, subsequently, of the pyruvate, essential for the synthesis of isoprenoids. This hypothesis was in accordance with that of Ramos et al. [2], supposing that response to salt stress goes through two stages where, in the first step, it accumulates glycerol and glycine betaine, and in a later time, it produces neutral lipid and carotenoid.

The pyruvate and G3P (glyceraldehyde-3-phosphate) will be converted to DXP (deoxyxylulose 5-phosphate) by DXS, catalyzing the first reaction in MEP (methylerythritol 4-phosphate) pathway [1]. Therefore, it is implicated in the synthesis of isoprenoids, such as carotenoids, chlorophylls, volatiles [64], and squalene [65]. The regulation of the MEP pathway required more clarification, resulting in the disagreement for the regulation of DXS. Lv et al. [21] found that the transcript level of DXS increased under nitrogen deprivation to provide more substrate to carotene synthesis. While Sánchez-Estudillo et al. [56] reported that the mRNA level of DXS decreased under nitrogen limitation on account of growth decrease, low photosynthetic activity, and chloroplast development. Our results showed a DXS increase at $24 \mathrm{~h}$, but it trended to stabilize after $72 \mathrm{~h}$ with lower expression level than non-stressed cells. The discrepancy in result between publications suggested the possibility of the existence of more than one isoform of DXS having different expression profiles and functions like among the microalgae, Botryococcus braunii, and plants (tomato, Arabidopsis, rice, maize, citrus fruit) $[64,66]$. Besides, the expression of DXS is subject to translational, posttranslational, and posttranscriptional modulations $[67,68]$. In fact, it was demonstrated that DXS expression was regulated by feedback exercised by isopentenyl diphosphate (IDP) and Dimethylallyl diphosphate (DMADP) $[67,69]$. It is important to recall the assumption that D. salina lost the mevalonate (MVA) pathway and uses only the MEP pathway to provide isoprenoids precursors [2]. Also, Sánchez-Estudillo and his collaborators supposed that carotenogenesis, dependent on the regulation of enzymes, is located in the final step of the 
MEP pathway [56]. This supposition was confirmed by the significant rise at $72 \mathrm{~h}$ of the expression level of $L C Y B$, which is involved in the cyclization of linear lycopene to $\beta$-carotene. Thus, the accumulation of this isoprene is directly related to the activity of this enzyme and the molecular regulation and control of its gene [20]. Our result was in accordance with those of Ramos et al. [18]. In D. bardawil, $L C Y B$ was regulated in salt stress, thanks to two salt regulated elements (SRE), having GT1GMSCAM4 sequence in the promoter and a GT-rich region in its first intron [70]. The promotor sequence of LCYB also contains a light-inducible element (GATABOX, CGCGBOXAT, SORLIP1AT) and W-boxes, a binding domain for the WRKY transcriptional factor [71]. WRKY transcription factor family is of high interest since it is involved in diverse biotic/abiotic stress response and developmental/physiological processes [70]. Moreover, our data showed that the increase in $L C Y B$ was concomitant with a rise in a lipid-associated protein CGP. It has a crucial role in maintaining the stability of $\beta C$-plastoglobules as it is localized at the periphery of the chloroplast [31-33], preventing the coalescence of the $\beta$-carotene globule, thanks to its hydrophilic layer, which covers the hydrophobic pigment core [33]. The gene coding for CGP is present in four different copies in D. salina 'Teodoresco' [32]. High light and/or nitrogen deficiency induces the accumulation of CGP in D. bardawil in parallel with $\beta$-carotene [33]. In accordance with our results, an increase in CGP mRNA expression was noticed during the first hours of nitrogen deprivation of $D$. bardawil [32]. This increase was associated with an accumulation of triacylglycerol (TAG) and $\beta$-carotene [72]. D. bardawil mobilizes TAG from the cytoplasm into the chloroplasts to form more plastoglobules [32]. In the non-carotenogenesis condition, the absence of these lipids globules was noticed.

Heat shock protein (HSP70B) is a $70 \mathrm{kDa}$ protein. It is a member of ATP-dependent molecular chaperones families, highly conserved and encoded by a single gene in green algae [73]. The increase in HSP70 expression lasting for $72 \mathrm{~h}$ of stress time can be explained by a cell requirement for chaperone molecule. A similar result was obtained by Yokthongwattana et al., 2001 [74], where the level of HSP70 gene expression increased immediately under irradiance stress by shifting cells from 75 to $2500 \mu \mathrm{mol}$ photon. $\mathrm{m}^{-2} \cdot \mathrm{s}^{-1}$ among D. salina. Authors revealed that cells lost D1 protein by photodamage; thus, it would be replaced by the accumulation of HSP70B, which could afford conformational protection to the dissembled PSII core complex. In fact, protein misfolding is a process under oxidative and environmental stress, leading to an increase in molecular chaperone and protease expression [75].

The RPE catalyzes the reversible epimerization reaction of D-ribulose-5-phosphate into D-xylulose-5-phosphate in the Calvin cycle. During these first three days of stress, the level of its mRNA was significantly less expressed in stressed condition than in unstressed one after $72 \mathrm{~h}$ of stress. Similarly, but at the proteomic level, the amount of this enzyme was also decreased among Dunaliella under stress [34] and among Nannochloropsis oceanica under nitrogen deprivation [76]. This means that the photosynthetic efficiency is affected by nitrogen amount [76], but, at the same time, the down-regulation of this enzyme allows the accumulation of xylulose-5P, which probably would serve as a substrate for G3P production in the pentose phosphate cycle [34].

In order to identify if these transcriptional changes go along with posttranslational ones, bioinformatics tools were used to analyze protein sequences of the two genes (CGP and LCYB) having the most increased transcriptional levels. Prediction of PTMs showed numerous possible phosphorylation, palmitoylation, and myristoylation sites, as well as sumoylation sites. Thes results corroborated the fine regulation of the two enzymes after their fold and the major regulatory role they have in modulating the ratio of carotenoid biosynthesis. Unlike plants, data concerning posttranslational regulation modalities of CGP and LCYB were not well studied for microalgae. In addition, the presence of SUMO protein in Dunaliella was not reported previously.

Posttranslational modification by SUMO is a major regulating mechanism for eukaryotic protein functions. SUMO becomes commonly covalently attached to specific targets (lysine residue) through a succession of molecular "handoffs" relating multienzyme cascades consisting of an E1 activating enzyme, an E2 conjugating enzyme, and an E3 ligase. Attachment of SUMO is known to control target functions, such as protein-protein interactions, protein-DNA interactions, and subcellular localization. 
Sumo regulates equally many important processes, such as signaling, transcription, DNA repair, and other stress responses. In plants, it was demonstrated that sumoylation plays an important role in reacting to stress and pathogens [77]. For microalga, three SUMO homologs and SUMO-related proteins were identified in $C$ reinhardii and were established to be essential for the survival of the strain under stress conditions [78]. Concerning the regulation of LCYB by sumoylation, recent research reported the detection of a recognition sequence for sumoylation in LCYB from Bixa orellana that could modulate enzyme activity or localization [79]. To the best of our knowledge, this is the first report for a possible regulation by the sumoylation of LCYB in Dunaliella sp., and to further investigate the attachment modalities between the two proteins, we tried to carry out a 3D modeling analysis. For this purpose, a crystal structure of geranylgeranyl reductase from a Sulfolobus acidocaldarius strain was used since it displays an acceptable sequence identity/coverage, and it was used in the previous reports of LCYB models. The overall structure was divided into two distinct domains: a catalytic domain involving a FAD-binding site, as well as a substrate-binding site and a transmembrane domain. In fact, several studies have shown that lycopene cyclases use FAD as a cofactor [80] and that many of the enzymes involved in lycopene and carotene transformations are membrane-bound [81]. We found that the binding site was not far from the membrane helices and that the FAD-binding domain existed in the diagonally opposite side of the enzyme (Figure 6a). The inspection of the putative SUMO interacting residue (K271), as well as sumoylation interaction motifs, showed that they were both located on the same side and were very close to each other and the FAD-binding site (Figure $7 \mathrm{~b}$ ). This observation could be interesting in understanding the regulation mechanism exerted by SUMO on LCYB, and the overall work is expected to help the future investigation of transcriptional/translational regulation studies in Dunaliella sp.

\section{Conclusions}

In this study, Dunaliella sp. was submitted to stress conditions by varying simultaneously the salinity, the light intensity, and the nitrogen availability. Mentioned conditions result in the deviation of the metabolism for the carotenoid accumulation. The latter could substitute chlorophyll with the advantage of preserving cell viability until roughly the end of the exponential phase. Flow cytometry analyses revealed that stressed and unstressed cells exhibited differences in their intrinsic and extrinsic characteristics. At the transcriptional level, the expression of genes, closely related to the synthesis and the accumulation of $\beta$-carotene, increased significantly. On the other hand, the inspection of the three-dimensional model of lycopene- $\beta$-cyclase, a key enzyme in the carotenoid synthesis pathway, highlighted possible further regulation by posttranslational modification, especially sumoylation.

Supplementary Materials: The following are available online at http://www.mdpi.com/2076-3417/9/24/5389/s1, Figure S1: Geomean of ranking values of the candidate reference genes based on the RefFinder algorithm (a); Average expression stability $\mathrm{M}$ values of remaining control genes based on GeNorm algorithm (b). The mean $\mathrm{Cq}$ of three independent replicate experiments was used to generate Data.

Author Contributions: Conceptualization, S.A., C.P., and I.F.; methodology, I.F.; software, H.B.H.; validation, H.B.H., M.B., and P.B.; formal analysis, H.B.H.; investigation, F.E.; resources, C.P.; data curation, H.B.H.; writing-Original draft preparation, F.E.; writing-Review and editing, F.E.; visualization, P.B.; supervision, S.A., C.P., and I.F.; project administration, C.P. and I.F.

Funding: This research did not receive any specific grant from funding agencies in the public, commercial, or not-for-profit sectors.

Acknowledgments: We are very grateful to David Gosset from the "Plateforme de Cytométrie en flux et imagerie cellulaire-P@CYFIC du Centre de Biophysique Moléculaire" (CNRS, Orléans, France) for his excellent technical assistance for Flow cytometry experiments.

Conflicts of Interest: The authors declare no conflict of interest. 


\section{References}

1. Ye, Z.-W.; Jiang, J.-G.; Wu, G.-H. Biosynthesis and regulation of carotenoids in Dunaliella: Progresses and prospects. Biotechnol. Adv. 2008, 26, 352-360. [CrossRef] [PubMed]

2. Ramos, A.A.; Polle, J.; Tran, D.; Cushman, J.C.; Jin, E.; Varela, J.C. The unicellular green alga Dunaliella salina Teod. as a model for abiotic stress tolerance: Genetic advances and future perspectives. Algae 2011, 26, 3-20. [CrossRef]

3. Chen, H.; Jiang, J.-G. Osmotic responses of Dunaliella to the changes of salinity. J. Cell. Physiol. 2009, 219, 251-258. [CrossRef] [PubMed]

4. Gong, M.; Bassi, A. Carotenoids from microalgae: A review of recent developments. Biotechnol. Adv. 2016, 34, 1396-1412. [CrossRef]

5. Merhan, O. The biochemistry and antioxidant properties of carotenoids. Carotenoids 2017, 5, 51.

6. García-González, M.; Moreno, J.; Manzano, J.C.; Florencio, F.J.; Guerrero, M.G. Production of Dunaliella salina biomass rich in 9-cis- $\beta$-carotene and lutein in a closed tubular photobioreactor. J. Biotechnol. 2005, 115, 81-90. [CrossRef]

7. Domonkos, I.; Kis, M.; Gombos, Z.; Ughy, B. Carotenoids, versatile components of oxygenic photosynthesis. Prog. Lipid Res. 2013, 52, 539-561. [CrossRef]

8. Ben-Amotz, A.; Shaish, A.; Avron, M. Mode of action of the massively accumulated beta-carotene of Dunaliella bardawil in protecting the alga against damage by excess irradiation. Plant Physiol. 1989, 91, 1040-1043. [CrossRef]

9. Raja, R.; Hemaiswarya, S.; Rengasamy, R. Exploitation of Dunaliella for $\beta$-carotene production. Appl. Microbiol. Biotechnol. 2007, 74, 517-523. [CrossRef]

10. Nishino, H.; Tokuda, H.; Murakoshi, M.; Satomi, Y.; Masuda, M.; Onozuka, M.; Yamaguchi, S.; Takayasu, J.; Tsuruta, J.; Okuda, M.; et al. Cancer prevention by natural carotenoids. BioFactors Oxf. Engl. 2000, 13, 89-94. [CrossRef]

11. Pasquet, V. Recherche Bioguidée de Molécules Anticancéreuses Issues de Microalgues Marines. Ph.D. Thesis, Université de La Rochelle, La Rochelle, France, 2011.

12. Jayappriyan, K.R.; Rajkumar, R.; Venkatakrishnan, V.; Nagaraj, S.; Rengasamy, R. In Vitro Anticancer Activity of Natural $\beta$-Carotene from Dunaliella Salina EU5891199 in PC-3 Cells. Biomed. Prev. Nutr. 2013, 3, $99-105$.

13. Yang, D.-J.; Lin, J.-T.; Chen, Y.-C.; Liu, S.-C.; Lu, F.-J.; Chang, T.-J.; Wang, M.; Lin, H.-W.; Chang, Y.-Y. Suppressive effect of carotenoid extract of Dunaliella salina alga on production of LPS-stimulated pro-inflammatory mediators in RAW264.7 cells via NF-kB and JNK inactivation. J. Funct. Foods 2013, 5, 607-615. [CrossRef]

14. Jaswir, I. Carotenoids: Sources, medicinal properties and their application in food and nutraceutical industry. J. Med. Plants Res. 2011, 5, 7119-7131.

15. Ben-Amotz, A.; Katz, A.; Avron, M. Accumulation of $\beta$-carotene in halotolerant algae: Purification and characterization of $\beta$-carotene-rich globules from Dunaliella bardawil (Chlorophyceae). J. Phycol. 1982, 18, 529-537. [CrossRef]

16. Chen, X.; Han, H.; Jiang, P.; Nie, L.; Bao, H.; Fan, P.; Lv, S.; Feng, J.; Li, Y. Transformation of $\beta$-lycopene cyclase genes from Salicornia europaea and Arabidopsis conferred salt tolerance in Arabidopsis and tobacco. Plant Cell Physiol. 2011, 52, 909-921. [CrossRef]

17. Cui, H.; Wang, Y.; Qin, S. Molecular evolution of lycopene cyclases involved in the formation of carotenoids in eukaryotic algae. Plant Mol. Biol. Report. 2011, 29, 1013-1020. [CrossRef]

18. Ramos, A.; Coesel, S.; Marques, A.; Rodrigues, M.; Baumgartner, A.; Noronha, J.; Rauter, A.; Brenig, B.; Varela, J. Isolation and characterization of a stress-inducible Dunaliella salina Lcy-beta gene encoding a functional lycopene beta-cyclase. Appl. Microbiol. Biotechnol. 2008, 79, 819-828. [CrossRef]

19. Fazeli, M.R.; Tofighi, H.; Madadkar-Sobhani, A.; Shahverdi, A.R.; Nejad-Sattari, T.; Mirzaie, S.; Jamalifar, H. Nicotine inhibition of lycopene cyclase enhances accumulation of carotenoid intermediates by Dunaliella salina CCAP 19/18. Eur. J. Phycol. 2009, 44, 215-220. [CrossRef]

20. Zhu, Y.-H.; Jiang, J.-G.; Chen, Q. Characterization of cDNA of lycopene beta-cyclase responsible for a high level of beta-carotene accumulation in Dunaliella salina. Biochem. Cell Biol. Biochim. Biol. Cell. 2008, 86, 285-292. [CrossRef] 
21. Lv, H.; Cui, X.; Wahid, F.; Xia, F.; Zhong, C.; Jia, S. Analysis of the Physiological and Molecular Responses of Dunaliella salina to Macronutrient Deprivation. PLoS ONE 2016, 11, e0152226. [CrossRef]

22. Mendoza, H.; Río, M.J.D.; Reina, G.G.; Ramazanov, Z. Low-temperature-induced $\beta$-carotene and fatty acid synthesis, and ultrastructural reorganization of the chloroplast in Dunaliella salina (Chlorophyta). Eur. J. Phycol. 1996, 31, 329-331. [CrossRef]

23. Lamers, P.P.; Janssen, M.; De Vos, R.C.H.; Bino, R.J.; Wijffels, R.H. Carotenoid and fatty acid metabolism in nitrogen-starved Dunaliella salina, a unicellular green microalga. J. Biotechnol. 2012, 162, 21-27. [CrossRef] [PubMed]

24. Yilancioglu, K.; Cokol, M.; Pastirmaci, I.; Erman, B.; Cetiner, S. Oxidative stress is a mediator for increased lipid accumulation in a newly isolated Dunaliella salina strain. PLoS ONE 2014, 9, e91957. [CrossRef] [PubMed]

25. Shaker, S. Effects of sulfur, iron and manganese starvation on growth, $\beta$-carotene production and lipid profile of Dunaliella salina. J. Young Pharm. 2017, 9, 43-46. [CrossRef]

26. Wongsnansilp, T.; Juntawong, N.; Wu, Z. Effects of phosphorus on the growth and chlorophyll fluorescence of a Dunaliella salina strain isolated from saline soil under nitrate limitation. J. Biol. Res. Boll. Della Soc. Ital. Biol. Sper. 2016, 89, 5866. [CrossRef]

27. Gomez, P.I.; Barriga, A.; Cifuentes, A.S.; Gonzalez, M.A. Effect of salinity on the quantity and quality of carotenoids accumulated by Dunaliella salina (strain CONC-007) and Dunaliella bardawil (strain ATCC 30861) Chlorophyta. Biol. Res. 2003, 36, 185-192. [CrossRef] [PubMed]

28. Rad, F.A.; Aksoz, N.; Hejazi, M.A. Effect of salinity on cell growth and $\beta$-carotene production in Dunaliella sp. isolates from Urmia Lake in northwest of Iran. Afr. J. Biotechnol. 2011, 10, 2282-2289.

29. Farhat, N.; Rabhi, M.; Falleh, H.; Jouini, J.; Abdelly, C.; Smaoui, A. Optimization of Salt Concentrations for a Higher Carotenoid Production in Dunaliella salina (chlorophyceae). J. Phycol. 2011, 47, 1072-1077. [CrossRef]

30. Lamers, P.P.; Janssen, M.; De Vos, R.C.H.; Bino, R.J.; Wijffels, R.H. Exploring and exploiting carotenoid accumulation in Dunaliella salina for cell-factory applications. Trends Biotechnol. 2008, 26, 631-638. [CrossRef]

31. Davidi, L.; Levin, Y.; Ben-Dor, S.; Pick, U. Proteome Analysis of Cytoplasmatic and Plastidic $\beta$-Carotene Lipid Droplets in Dunaliella bardawil. Plant Physiol. 2015, 167, 60-79. [CrossRef]

32. Davidi, L.; Shimoni, E.; Khozin-Goldberg, I.; Zamir, A.; Pick, U. Origin of $\beta$-carotene-rich plastoglobuli in Dunaliella bardawil. Plant Physiol. 2014, 164, 2139-2156. [CrossRef] [PubMed]

33. Katz, A.; Jimenez, C.; Pick, U. Isolation and characterization of a protein associated with carotene globules in the alga Dunaliella bardawil. Plant Physiol. 1995, 108, 1657-1664. [CrossRef] [PubMed]

34. Ben Amor, F.; Elleuch, F.; Ben Hlima, H.; Garnier, M.; Saint-Jean, B.; Barkallah, M.; Pichon, C.; Abdelkafi, S.; Fendri, I. Proteomic analysis of the Chlorophyta Dunaliella new strain AL-1 revealed global changes of metabolism during high carotenoid production. Mar. Drugs 2017, 15, 293. [CrossRef] [PubMed]

35. Chtourou, H.; Dahmen, I.; Jebali, A.; Karray, F.; Hassairi, I.; Abdelkafi, S.; Ayadi, H.; Sayadi, S.; Dhouib, A. Characterization of Amphora sp., a newly isolated diatom wild strain, potentially usable for biodiesel production. Bioprocess Biosys. Eng. 2015, 38, 1381-1392. [CrossRef] [PubMed]

36. Wellburn, A.R.; Lichtenthaler, H. Formulae and Program to Determine Total Carotenoids and Chlorophylls A and B of Leaf Extracts in Different Solvents. In Advances in Photosynthesis Research; Advances in Agricultural Biotechnology; Springer: Dordrecht, The Netherlands, 1984; pp. 9-12. ISBN 978-90-247-2943-2.

37. Mendoza, H.; De la Jara, A.; Freijanes, K.; Carmona, L.; Ramos, A.A.; de Sousa Duarte, V.; Varela, S.; Carlos, J. Characterization of Dunaliella salina strains by flow cytometry: A new approach to select carotenoid hyperproducing strains. Electron. J. Biotechnol. 2008, 11, 5-6. [CrossRef]

38. Dammak, M.; Haase, S.M.; Miladi, R.; Ben Amor, F.; Barkallah, M.; Gosset, D.; Pichon, C.; Huchzermeyer, B.; Fendri, I.; Denis, M.; et al. Enhanced lipid and biomass production by a newly isolated and identified marine microalga. Lipids Health Dis. 2016, 15, 209. [CrossRef]

39. Chen, H.; Lao, Y.-M.; Jiang, J.-G. Effects of salinities on the gene expression of a (NAD+)-dependent glycerol-3-phosphate dehydrogenase in Dunaliella salina. Sci. Total Environ. 2011, 409, 1291-1297. [CrossRef]

40. Chen, X.-J.; Zhang, X.-H.; Hu, L.-D.; Zhang, J.-Q.; Jiang, Y.; Yang, Y.; Yan, Y.-B. DsCaf1 is involved in environmental stress response of Dunaliella salina. Int. J. Biol. Macromol. 2016, 82, 369-374. [CrossRef]

41. Li, X.; Zhang, D.; Li, H.; Gao, B.; Yang, H.; Zhang, Y.; Wood, A.J. Characterization of reference genes for RT-qPCR in the desert moss Syntrichia caninervis in response to abiotic stress and desiccation/rehydration. Front. Plant Sci. 2015, 6, 38. [CrossRef] 
42. Xie, F.; Xiao, P.; Chen, D.; Xu, L.; Zhang, B. miRDeepFinder: A miRNA analysis tool for deep sequencing of plant small RNAs. Plant Mol. Biol. 2012, 80, 75-84. [CrossRef]

43. Vandesompele, J.; Preter, K.D.; Pattyn, F.; Poppe, B.; Roy, N.V.; Paepe, A.D.; Speleman, F. Accurate normalization of real-time quantitative RT-PCR data by geometric averaging of multiple internal control genes. Genome Biol. 2002, 3, 1-12. [CrossRef] [PubMed]

44. Pfaffl, M.W. A new mathematical model for relative quantification in real-time RT-PCR. Nucleic Acids Res. 2001, 29, e45. [CrossRef] [PubMed]

45. Sievers, F.; Wilm, A.; Dineen, D.; Gibson, T.J.; Karplus, K.; Li, W.; Lopez, R.; McWilliam, H.; Remmert, M.; Söding, J.; et al. Fast, scalable generation of high-quality protein multiple sequence alignments using Clustal Omega. Mol. Syst. Biol. 2011, 7, 539. [CrossRef] [PubMed]

46. Ben Amor, F.; Ben Hlima, H.; Abdelkafi, S.; Fendri, I. Insight into Arthrospira platensis $\Delta 9$ desaturase: A key enzyme in poly-unsaturated fatty acid synthesis. Mol. Biol. Rep. 2018, 45, 1873-1879. [CrossRef]

47. Xia, J.-X.; Ikeda, M.; Shimizu, T. ConPred_elite: A highly reliable approach to transmembrane topology predication. Comput. Biol. Chem. 2004, 28, 51-60. [CrossRef]

48. Laskowski, R.A.; MacArthur, M.W.; Thornton, J.M. PROCHECK: Validation of Protein-Structure Coordinates. Available online: http://xrpp.iucr.org/Fb/ch21o4v0001/ (accessed on 13 February 2018).

49. Tian, W.; Chen, C.; Lei, X.; Zhao, J.; Liang, J. CASTp 3.0: Computed atlas of surface topography of proteins. Nucleic Acids Res. 2018, 46, W363-W367. [CrossRef]

50. Shin, W.-H.; Kim, J.-K.; Kim, D.-S.; Seok, C. GalaxyDock2: Protein-ligand docking using beta-complex and global optimization. J. Comput. Chem. 2013, 34, 2647-2656. [CrossRef]

51. Pedrós, R.; Moya, I.; Goulas, Y.; Jacquemoud, S. Chlorophyll fluorescence emission spectrum inside a leaf. Photochem. Photobiol. Sci. 2008, 7, 498-502. [CrossRef]

52. Nonomura, A.M.; Coder, D.M. Improved Phycocatalysis of Carotene Production by Flow Cytometry and Cell Sorting. Biocatalysis 1988, 1, 333-338. [CrossRef]

53. Ukibe, K.; Katsuragi, T.; Tani, Y.; Takagi, H. Efficient screening for astaxanthin-overproducing mutants of the yeast Xanthophyllomyces dendrorhous by flow cytometry. FEMS Microbiol. Lett. 2008, 286, 241-248. [CrossRef]

54. Ahn, J.-W.; Kim, K.-J. Crystal structure of 1'-OH-carotenoid 3,4-desaturase from Nonlabens dokdonensis DSW-6. Enzym. Microb. Technol. 2015, 77, 29-37. [CrossRef] [PubMed]

55. Shang, Q.; Xu, C.; Zhang, J.; Zhang, X.; Tu, X. Solution structure of SUMO from Trypanosoma brucei and its interaction with Ubc9. Proteins Struct. Funct. Bioinform. 2009, 76, 266-269. [CrossRef] [PubMed]

56. Sánchez-Estudillo, L.; Freile-Pelegrin, Y.; Rivera-Madrid, R.; Robledo, D.; Narváez-Zapata, J.A. Regulation of two photosynthetic pigment-related genes during stress-induced pigment formation in the green alga. Dunaliella salina. Biotechnol. Lett. 2006, 28, 787-791. [CrossRef] [PubMed]

57. Mishra, A.; Jha, B. Isolation and characterization of extracellular polymeric substances from micro-algae Dunaliella salina under salt stress. Bioresour. Technol. 2009, 100, 3382-3386. [CrossRef] [PubMed]

58. Zhao, L.; Gong, W.; Chen, X.; Chen, D. Characterization of genes and enzymes in Dunaliella salina involved in glycerol metabolism in response to salt changes. Phycol. Res. 2013, 61, 37-45. [CrossRef]

59. Xia, B.-B.; Wang, S.-H.; Duan, J.-B.; Bai, L.-H. The relationship of glycerol and glycolysis metabolism patway under hyperosmotic stress in Dunaliella salina. Cent. Eur. J. Biol. 2014, 9, 901-908. [CrossRef]

60. Fachet, M.; Hermsdorf, D.; Rihko-Struckmann, L.; Sundmacher, K. Flow cytometry enables dynamic tracking of algal stress response: A case study using carotenogenesis in Dunaliella salina. Algal Res. 2016, 13, 227-234. [CrossRef]

61. Park, S.; Polle, J.E.W.; Melis, A.; Lee, T.K.; Jin, E. Up-regulation of photoprotection and PSII-repair gene expression by irradiance in the unicellular green alga Dunaliella salina. Mar. Biotechnol. 2006, 8, 120-128. [CrossRef]

62. Ruan, K.; Duan, J.; Bai, F.; Lemaire, M.; Ma, X.; Bai, L. Function of Dunaliella salina (Dunaliellaceae) enolase and its expression during stress. Eur. J. Phycol. 2009, 44, 207-214. [CrossRef]

63. Polle, J.E.W.; Neofotis, P.; Huang, A.; Chang, W.; Sury, K.; Wiech, E.M. Carbon Partitioning in Green Algae (Chlorophyta) and the Enolase Enzyme. Metabolites 2014, 4, 612-628. [CrossRef]

64. Peng, G.; Wang, C.; Song, S.; Fu, X.; Azam, M.; Grierson, D.; Xu, C. The role of 1-deoxy-d-xylulose-5-phosphate synthase and phytoene synthase gene family in citrus carotenoid accumulation. Plant Physiol. Biochem. 2013, 71, 67-76. [CrossRef] [PubMed] 
65. Kajikawa, M.; Kinohira, S.; Ando, A.; Shimoyama, M.; Kato, M.; Fukuzawa, H. Accumulation of squalene in a microalga Chlamydomonas reinhardtii by genetic modification of squalene synthase and squalene epoxidase genes. PLoS ONE 2015, 10, e0120446. [CrossRef] [PubMed]

66. Matsushima, D.; Jenke-Kodama, H.; Sato, Y.; Fukunaga, Y.; Sumimoto, K.; Kuzuyama, T.; Matsunaga, S.; Okada, S. The single cellular green microalga Botryococcus braunii, race B possesses three distinct 1-deoxy-d-xylulose 5-phosphate synthases. Plant Sci. 2012, 185-186, 309-320. [CrossRef] [PubMed]

67. Ghirardo, A.; Wright, L.P.; Bi, Z.; Rosenkranz, M.; Pulido, P.; Rodríguez-Concepción, M.; Niinemets, Ü.; Brüggemann, N.; Gershenzon, J.; Schnitzler, J.-P. Metabolic flux analysis of plastidic isoprenoid biosynthesis in poplar leaves emitting and nonemitting isoprene. Plant Physiol. 2014, 165, 37-51. [CrossRef]

68. Guevara-García, A.; San Román, C.; Arroyo, A.; Cortés, M.E.; de la Luz Gutiérrez-Nava, M.; León, P. Characterization of the Arabidopsis clb6 Mutant Illustrates the Importance of Posttranscriptional Regulation of the Methyl-d-Erythritol 4-Phosphate Pathway. Plant Cell 2005, 17, 628-643. [CrossRef]

69. Banerjee, A.; Wu, Y.; Banerjee, R.; Li, Y.; Yan, H.; Sharkey, T.D. Feedback Inhibition of Deoxy-d-xylulose-5-phosphate Synthase Regulates the Methylerythritol 4-Phosphate Pathway. J. Biol. Chem. 2013, 288, 16926-16936. [CrossRef]

70. Liang, M.-H.; Lu, Y.; Chen, H.-H.; Jiang, J.-G. The salt-regulated element in the promoter of lycopene $\beta$-cyclase gene confers a salt regulatory pattern in carotenogenesis of Dunaliella bardawil. Environ. Microbiol. 2017, 19, 982-989. [CrossRef]

71. Liang, M.-H.; Jiang, J.-G. Analysis of carotenogenic genes promoters and WRKY transcription factors in response to salt stress in Dunaliella bardawil. Sci. Rep. 2017, 7, 37025. [CrossRef]

72. Rabbani, S.; Beyer, P.; Lintig, J.V.; Hugueney, P.; Kleinig, H. Induced $\beta$-Carotene Synthesis Driven by Triacylglycerol Deposition in the Unicellular Alga Dunaliella bardawil. Plant Physiol. 1998, 116, 1239-1248. [CrossRef]

73. Chiu, C.-C.; Chen, L.-J.; Su, P.-H.; Li, H. Evolution of chloroplast J proteins. PLoS ONE 2013, 8, e70384. [CrossRef]

74. Yokthongwattana, K.; Chrost, B.; Behrman, S.; Casper-Lindley, C.; Melis, A. Photosystem II Damage and Repair Cycle in the Green Alga Dunaliella salina: Involvement of a Chloroplast-Localized HSP70. Plant Cell Physiol. 2001, 42, 1389-1397. [CrossRef] [PubMed]

75. Trösch, R.; Mühlhaus, T.; Schroda, M.; Willmund, F. ATP-dependent molecular chaperones in plastids-More complex than expected. Biochim. Biophys. Acta-Bioenerg. 2015, 1847, 872-888. [CrossRef] [PubMed]

76. Dong, H.-P.; Williams, E.; Wang, D.; Xie, Z.-X.; Hsia, R.; Jenck, A.; Halden, R.; Li, J.; Chen, F.; Place, A.R. Responses of Nannochloropsis oceanica IMET1 to Long-Term Nitrogen Starvation and Recovery1. Plant Physiol. 2013, 162, 1110-1126. [CrossRef] [PubMed]

77. Enserink, J.M. Sumo and the cellular stress response. Cell Div. 2015, 10, 4. [CrossRef]

78. Knobbe, A.R.; Horken, K.M.; Plucinak, T.M.; Balassa, E.; Cerutti, H.; Weeks, D.P. SUMOylation by a stress-specific small ubiquitin-like modifier E2 conjugase is essential for survival of Chlamydomonas reinhardtii under stress conditions. Plant Physiol. 2015, 167, 753-765. [CrossRef]

79. Trujillo-Hdz, J.A.; Cárdenas-Conejo, Y.; Turriza, P.E.; Aguilar-Espinosa, M.; Carballo-Uicab, V.; Garza-Caligaris, L.E.; Comai, L.; Rivera-Madrid, R. Functional polymorphism in lycopene beta-cyclase gene as a molecular marker to predict bixin production in Bixa orellana L. (achiote). Mol. Breed. 2016, 36, 135. [CrossRef]

80. Yu, Q.; Schaub, P.; Ghisla, S.; Al-Babili, S.; Krieger-Liszkay, A.; Beyer, P. The lycopene cyclase CrtY from Pantoea ananatis (formerly Erwinia uredovora) catalyzes an FADred-dependent non-redox reaction. J. Biol. Chem. 2010, 285, 12109-12120. [CrossRef]

81. Moise, A.R.; Al-Babili, S.; Wurtzel, E.T. Mechanistic aspects of carotenoid biosynthesis. Chem. Rev. 2014, 114, 164-193. [CrossRef]

(C) 2019 by the authors. Licensee MDPI, Basel, Switzerland. This article is an open access article distributed under the terms and conditions of the Creative Commons Attribution (CC BY) license (http://creativecommons.org/licenses/by/4.0/). 